\title{
Cancer Patient
}

National Cancer Institute

\section{Source}

National Cancer Institute. Cancer Patient. NCI Thesaurus. Code C19700.

A person who receives medical care for the purpose of treating, diagnosing or preventing cancer. 